\title{
Multiscale satellite and spatial information and analysis framework in support of a large-area forest monitoring and inventory update
}

\author{
Michael A. Wulder • Joanne C. White • \\ Mark D. Gillis • Nick Walsworth • \\ Matthew C. Hansen • Peter Potapov
}

Received: 13 June 2009 / Accepted: 29 October 2009 / Published online: 12 November 2009

(C) The Author(s) 2009. This article is published with open access at Springerlink.com

\begin{abstract}
Many countries undertake a national forest inventory to enable statistically valid monitoring in support of national and international reporting of forest conditions and change. Canada's National Forest Inventory (NFI) program is designed to operate on a 10-year remeasurement cycle, with an interim report produced at the 5-year mid-point. The NFI is a sample-based inventory, with approximately $18,8502 \times 2-\mathrm{km}$ photo plots across the country, distributed on a $20 \times 20-\mathrm{km}$ grid of sample points; these photo plots are the primary data source for the NFI. Capacity to provide annual monitoring information is required to keep policy and decision makers apprised of current forest conditions. In this study, we implemented a multistage monitoring framework and used a Moderate Resolution Imaging Spectroradiometer (MODIS) change product to successfully identify $78 \%$ of the changes in forest cover area that were captured with a Landsat change detection approach. Of the NFI photo plots that
\end{abstract}

M. A. Wulder $(\varangle)$. J. C. White .

M. D. Gillis · N. Walsworth

Canadian Forest Service (Pacific Forestry Centre),

Natural Resources Canada, 506 West Burnside Rd.,

Victoria, BC V8Z 1M5, Canada

e-mail: mike.wulder@nrcan.gc.ca

M. C. Hansen · P. Potapov

Geographic Information Science Center of Excellence,

South Dakota State University, Brookings, SD, USA were identified by both the Landsat and MODIS approaches as having changes in forest cover, the proportion of change area within the plots was similar $\left(R^{2}=0.78\right)$. Approximately $70 \%$ of the Landsat-derived change events occupied less than $40 \%$ of a single MODIS pixel, and more than $90 \%$ of the change events of this size were successfully detected with the MODIS product. Finally, MODIS estimates of the proportion of forest cover change at the NFI photo plot level were comparable to change estimates for the ecoregions as a whole $\left(R^{2}=0.95\right)$. High-temporal, lowspatial resolution imagery such as MODIS, in combination with other remotely sensed data sources, can provide information on disturbance events within a national forest inventory remeasurement cycle, thereby satisfying the interim information needs of policy and decision makers as well as the requirements of national and international reporting commitments.

Keywords Forest inventory $\cdot$ MODIS • Landsat - Monitoring - Change detection • Inventory update

\section{Introduction}

Canada is a large nation, nearly one billion hectares in size. Forests and other wooded land occupy $40 \%$ of the nation's total land area or 
approximately $65 \%$ of the total land area that has the potential to support forests. With approximately $10 \%$ of the world's forests and $30 \%$ of the world's boreal forest, Canada is committed to responsible stewardship of forests and forested environments. Canada's provincial and territorial agencies have ownership and direct management responsibilities for $78 \%$ of the country's forest land. Each province or territory undertakes its own forest inventory and monitoring programs according to its own standards (Gillis 2001) and these inventory efforts are typically restricted to forest land that is capable of producing a merchantable stand within a reasonable length of time. The federal government's role in forest inventory is mainly associated with research and development, inventory of federally administered forest lands, and compilation and reporting of a national forest inventory. The latter has been accomplished by compiling existing provincial and territorial inventories, as well as satellite imagery and other data where provincial and territorial forest inventory data were not available (e.g., parks, nonproductive forest land) (Power and Gillis 2006). While this data-compilation approach is cost effective, it does not provide timely information on the nature and rate of change of Canada's forests nor does it provide a satisfactory basis from which to monitor change.

In response to emerging national and international information needs, Canada introduced a new National Forest Inventory (NFI) program in 2000 (Gillis 2001). The NFI is designed to "assess and monitor the extent, state, and sustainable development of Canada's forests in a timely and accurate manner" (Gillis et al. 2005). The new NFI has a plot-based design, consisting of permanent observational units on a national grid that represent $1 \%$ of Canada's forested area. Information within each of these permanent observation units is collected to uniform standards from photo- and ground-based observations and measurements, enabling consistent reporting of forest status and trends across the country (Gillis et al. 2005). Units will be repeatedly sampled on a 10 -year cycle, with provisions for periodic (5-year) reporting. To facilitate remeasurement, sample units are systematically assigned to a subset of two units (panels), with each panel representing a valid sample of the population that can be used to calculate change estimates and report on trends. Each panel is planned to be remeasured over a 5-year period, allowing the cost and effort of remeasurement to be distributed over the 10-year cycle of the inventory (Gillis et al. 2005). Units in non-measured panels are to be monitored for major disturbances each year and updated as required. Canada's NFI exemplifies a large-area forest monitoring program that integrates general forest characterization with detailed sample information (Wulder et al. 2004).

The structure, composition, and function of forests are dynamic, and this dynamism is often associated with disturbance events (e.g., insect, fire) or management interventions (e.g., harvest) (Bormann and Likens 1979). Many of the management activities indicated in Fig. 1 are discrete in time and space, and forest simulation models (e.g., growth and yield) are typically used to characterize forest attributes and project them into the future until such time as a remeasurement of inventory attributes is complete (Peng 2000). The majority of Canada's forested area is characterized by slow growth rates (Metsaranta and Lieffers 2009), making a longer inventory cycle appropriate for capturing the characteristically small incremental changes in growth. Notwithstanding this typically slow rate of change, the stochastic nature of forest disturbance poses a challenge to large-area forest inventory monitoring programs.

In order to satisfy the information needs of Canada's numerous national and international reporting obligations, spatially extensive accounting of forest disturbances is required on an annual basis. Remotely sensed data, available in a range of spatial and temporal resolutions, may enable the ongoing collection of information on disturbance events in Canada's forests (e.g., location, size, date). For example, the Canadian Wildland Fire Information System (CWFIS) applies the Fire Monitoring, Mapping, and Modeling (FireM3) system at the national level (Lee et al. 2002; Englefield et al. 2004). FireM3 uses remotely sensed data, such as Moderate Resolution Imaging Spectroradiometer (MODIS), to detect active fires (hotspots) on a daily basis, and CWFIS makes this information publicly available and 
Fig. 1 Forest management cycle

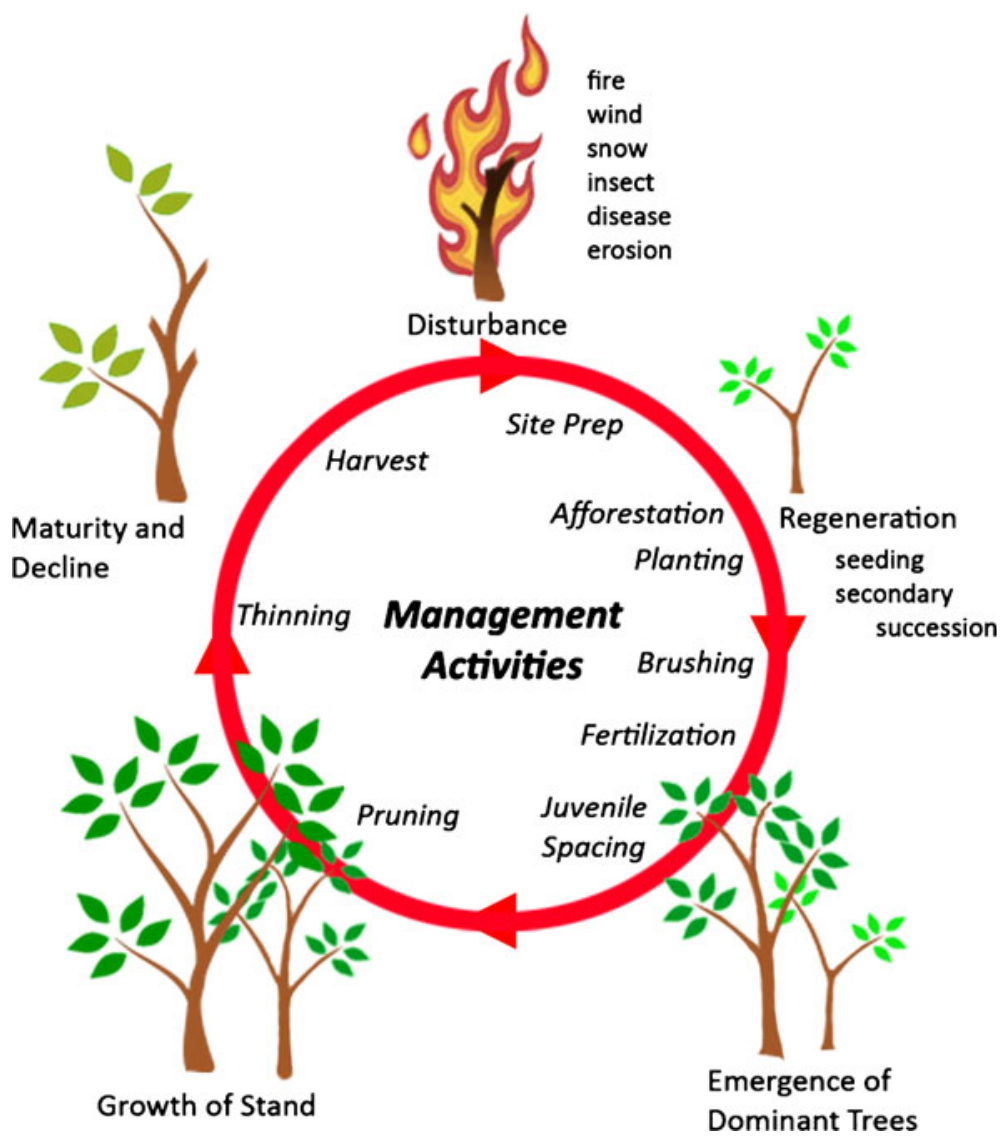

integrates it with other data to guide the acquisition of additional imagery, which is ultimately used to delineate fire perimeters and estimate burned area (deGroot et al. 2007).

Remote sensing is an important data source for monitoring the impacts of landscape disturbance. Tradeoffs in sensor design are often made to balance spatial detail with frequency of image acquisition, limiting capacity to monitor changes effectively (Hilker et al. 2009). The MODIS sensor onboard the Terra satellite has been acquiring daily imagery of the Earth since the year 2000. Designed to provide data for regional and global studies associated with biogeochemistry, energy balance, land cover, and ecosystem change (Justice et al. 2002), MODIS data products have been in continuous release and are freely available. This data source allows end users to exploit the MODIS sensor's high frequency of image capture and large-area coverage, resulting in the generation of seasonal, continental, cloud-free datasets.

MODIS data have been used for a wide range of forest monitoring applications, including mapping and detecting general changes in forest cover (Hansen et al. 2003, 2008a, b; Potapov et al. 2008) and more specifically forest harvesting (Jin and Sader 2005; Bucha and Stibig 2008). MODIS has also been used to detect and map forest fires (Hawbaker et al. 2008; Peckham et al. 2008; Cuevas-Gonzàlez et al. 2009), to estimate biomass (Anaya et al. 2009; Baccini et al. 2008) and gross primary production (Coops et al. 2009; $\mathrm{Wu}$ et al. 2009), and to monitor vegetation phenology (Ahl et al. 2006; Kim 2008). More recently, methods have been developed to combine the temporal frequency of MODIS data with the spatial resolution of Landsat, either through a decision-tree approach (e.g., Hansen et al. 2008a; Potapov et al. 2008) or through a data fusion 
approach (Gao et al. 2006; Hilker et al. 2009) for the purposes of mapping forest change.

The Canadian Forest Service is interested in using high-temporal, low-spatial resolution imagery such as MODIS, in combination with other data sources, to provide information on major forest changes (primarily disturbances) within the NFI remeasurement cycle. The framework for incorporating this high-temporal, low-spatial resolution data into the current NFI remeasurement context is summarized in Fig. 2. MODIS data, or data with a similar temporal and spatial resolution, may be used to detect and time stamp change events. The cause and spatial extent of the change events could then be refined using more detailed data, such as Landsat. Through the normal remeasurement cycle of the NFI, change events would eventually be evaluated with aerial photography or high spatial resolution satellite imagery, in order to accurately delineate the disturbance and update the photo plots and the appropriate NFI attributes. A database that stores the MODISderived change events could be created to support inventory audits and enable otherwise unavailable insights regarding interannual changes in forest conditions.

The goal of this study is to assess the utility and resolvability of MODIS for detecting change events which occurred between 2000 and 2005 in a boreal forest environment and for providing interim information for assessing changes to forest cover area within NFI photo plots and broader ecological units. To address this goal, we develop a framework that exploits the information in a forest cover change product generated from annual, large-area coverage MODIS data, and assess the utility of this MODIS product for capturing changes in forest cover within NFI photo plots and within broader ecological units. We demonstrate a prototype of this framework over a sample of

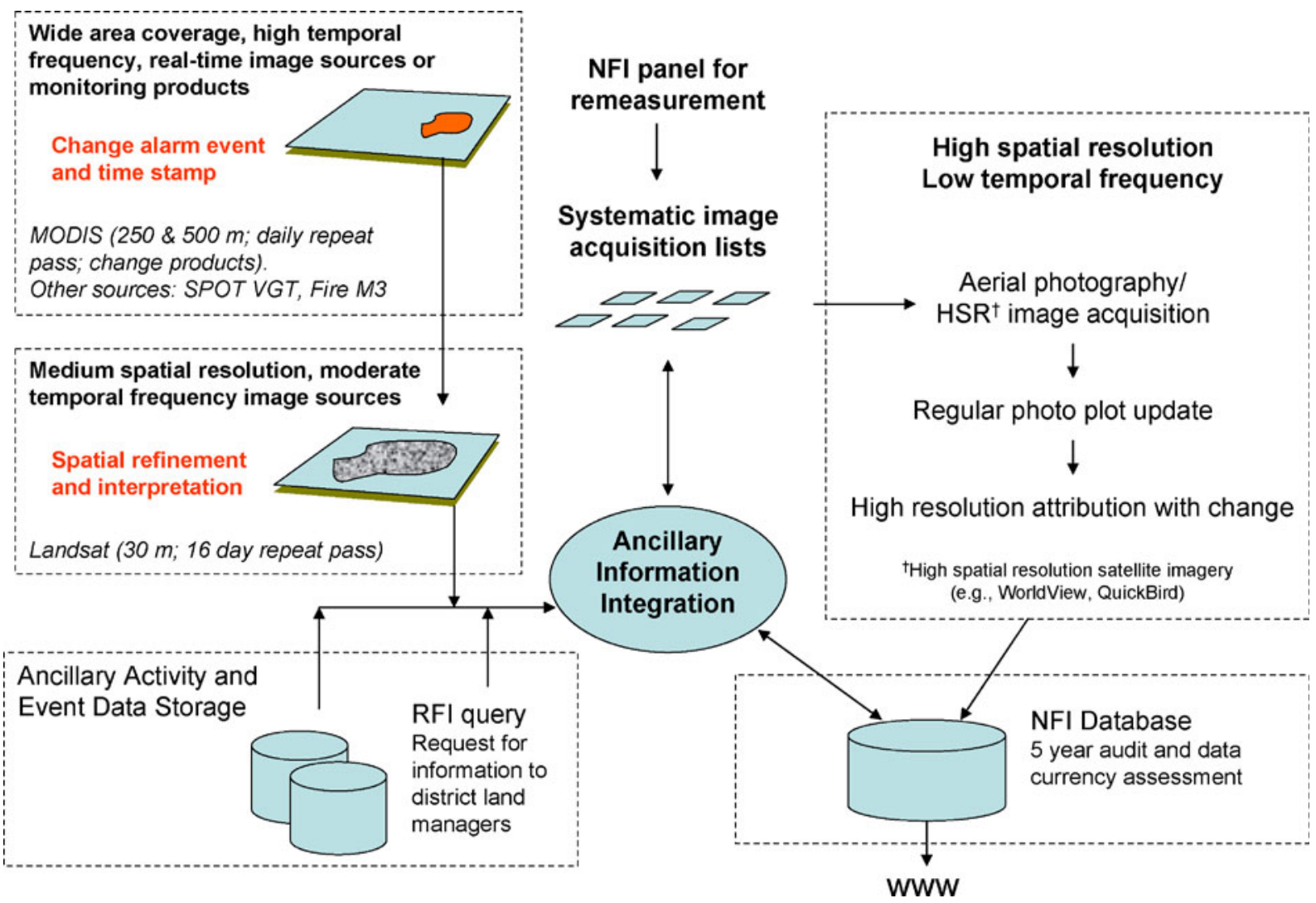

Fig. 2 Framework for integrating MODIS imagery into the NFI remeasurement cycle 
photo plots in an area of the boreal forest in Ontario, Canada $\left(850,000 \mathrm{~km}^{2}\right)$ and capture changes in forest cover that occurred between 2000 and 2005. MODIS- and Landsat-derived forest cover change events are compared in order to assess the capability of the MODIS product to identify both the location and amount of forest cover change.

\section{Methods}

\section{Study area}

Our analysis focused on an $850,000-\mathrm{km}^{2}$ forested area of the province of Ontario, Canada (Fig. 3).

This area is part of the spatially extensive Boreal
Shield Ecozone and is characterized by long, cold winters and short, warm summers. Over $80 \%$ of the ecozone is forested, with undulating topography and a mosaic of uplands and associated wetlands and numerous small- and medium-sized lakes (Ecological Stratification Working Group 1996).

\section{Data}

\section{NFI and ancillary data}

Approximately 2,170 NFI photo plots were located within the study area and represented circa year 2000 forest conditions. For more details concerning the $25 \mathrm{key}$ attributes reported in the NFI, as well as the sample design and the

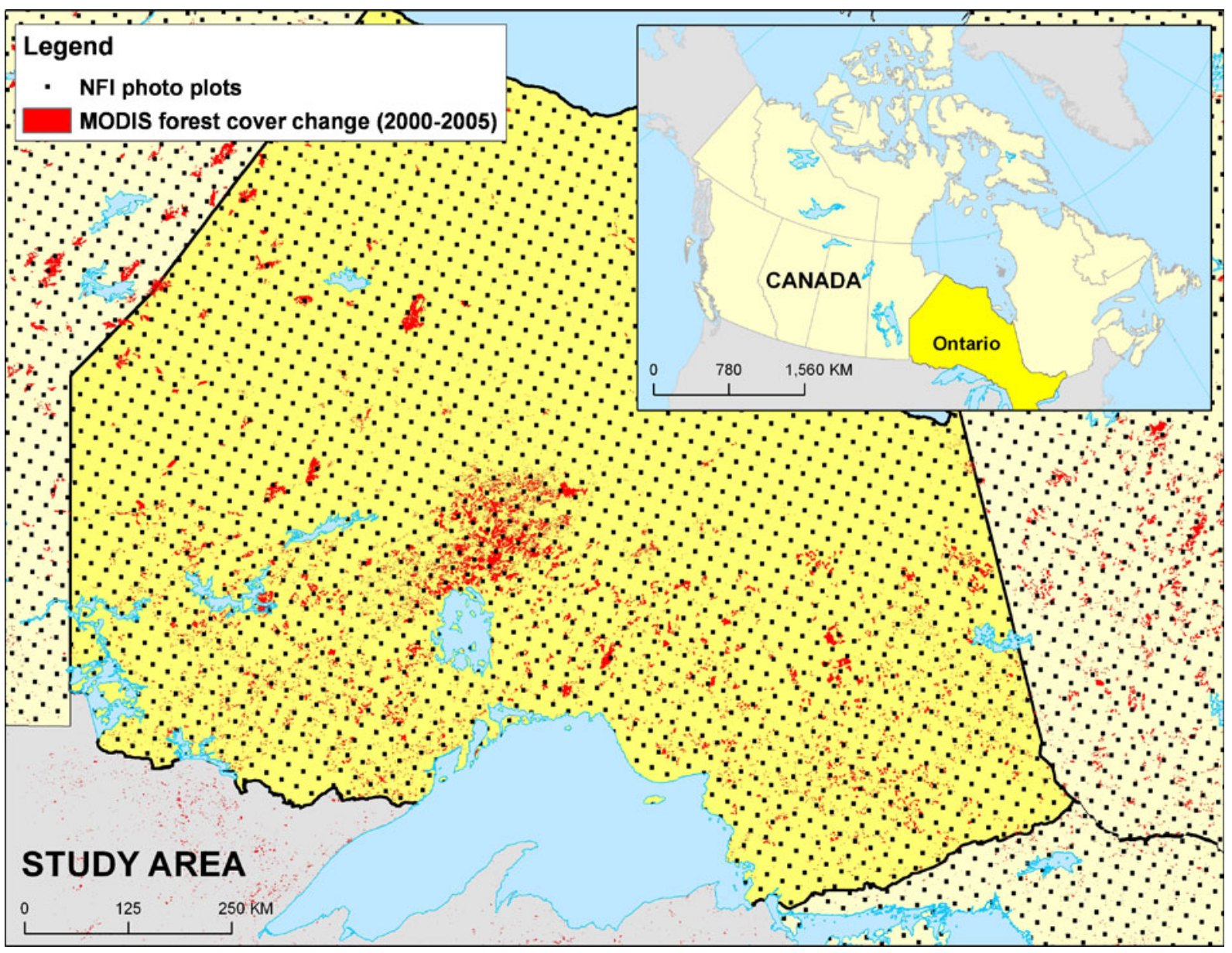

Fig. 3 Study area located in the forest-dominated area of Ontario, Canada 
Table 1 Ancillary data sources used to assess change events identified by Landsat change detection process

\begin{tabular}{ll}
\hline Data type & Sources \\
\hline Base data (time 1) & NFI photo plots \\
Remotely sensed data sources & Landsat ETM circa 2000 \\
& Landsat TM 2005-2007 \\
& SPOT Pan Sharpened Orthomosaics 2006-7 \\
& ASTER \\
Forest management data & Ontario provincial management forest inventory data \\
& Annual forest depletions data (2002-2005) \\
& (harvesting, insect damage, fires) \\
Other & Land cover (EOSD circa 2000) \\
& WRI 2000-2005 anthropogenic depletion \\
& VGT Fire M3 large fire data base 1996-2005 \\
\hline
\end{tabular}

remeasurement framework, readers are referred to Gillis et al. (2005). There are approximately $18,8502 \times 2-\mathrm{km}$ photo plots across the country, distributed on a $20 \times 20-\mathrm{km}$ grid of sample points (Fig. 3). The photo plots are the primary data source for the NFI (Gillis et al. 2005). In addition to the NFI data, a variety of ancillary data sources (Table 1) were used in this study as calibration and validation data.

\section{Landsat data}

Three Landsat Enhanced Thematic Mapper Plus (ETM+) and Thematic Mapper (TM) image pairs (representing Time 1 (T1) and Time 2 (T2)) were acquired, as listed in Table 2. Preprocessing for the Landsat image pairs included between-sensor DN conversion (to account for differences in TM gain, offset, spectral response function, and signalto-noise ratio), correction to top-of-atmosphere reflectance, and image-to-image normalization as detailed in Han et al. (2007). Finally, each image pair was co-registered using a second order polynomial and nearest neighbor resampling, resulting in an RMS error that was less than $15 \mathrm{~m}$ for each image pair.

Table 2 Landsat images used to calculate wetness difference indices

\begin{tabular}{lll}
\hline $\begin{array}{l}\text { Landsat WRS } \\
\text { path/row }\end{array}$ & $\begin{array}{l}\text { Time 1 (T1) } \\
\text { image }\end{array}$ & $\begin{array}{l}\text { Time 2 (T2) } \\
\text { image }\end{array}$ \\
\hline P20R25 & ETM Aug 21 2001 & TM5 Aug 8 2005 \\
P21R27 & ETM Aug 21 2001 & $\begin{array}{l}\text { TM5 Aug 5 2007 } \\
\text { P27R25 }\end{array}$ \\
\hline
\end{tabular}

\section{MODIS data}

The MODIS sensor has 36 spectral bands inclusive of the legacy bands from Landsat, with additional bands in the short- and long-wave infrared. Of the seven bands primarily used for land surface mapping, bands 3 to 7 (with a 500-m spatial resolution) are centered at $648,858,470,555,1240$, 1640, and $2130 \mathrm{~nm}$. Bands 1 and 2 have a 250-m spatial resolution and are centered on the red $(620-670 \mathrm{~nm})$ and infrared $(841-876 \mathrm{~nm})$ portions of the spectrum; they are designed to service the global Normalized Difference Vegetation Index (NDVI) products.

MODIS Vegetation Continuous Field (VCF) products contain proportional per-pixel estimates of vegetation cover (Hansen et al. 2003), and the methods used to generate these products have been extended to map annual forest canopy depletion using trajectory metrics derived from a monthly sequence of MODIS composites (Potapov et al. 2008). The VCF change product is an attempt to extend the work on static percent tree cover characterizations to establish sub-pixel percent forest cover characterizations. Prototype studies have shown satisfactory results for large change events, but less so with smaller events (Zhan et al. 2002; Morton et al. 2005; Lunetta et al. 2006).

Image processing

\section{Landsat change detection}

The primary source for identifying change events between 2000 and 2005 was a wetness difference 
index (WDI) generated from the Landsat ETM+ and TM image pairs listed in Table 2. The WDI is calculated by first generating the Tasseled Cap Transformation (TCT), which reduces the six reflectance channels of the Landsat imagery into three components: brightness, greenness, and wetness (Crist and Cicone 1984). The wetness TCT component has demonstrated utility for detecting and mapping forest disturbance (Skakun et al. 2003; Hais et al. 2009; Wang and $\mathrm{Xu}$ 2009). The wetness component for the most recent image date (T2) is subtracted from the wetness component for the first image date (T1) (Wulder et al. 2006). A threshold is then applied to the wetness difference values using an iterative process, enabled by the calibration data sources listed in Table 1. The threshold is selected to represent those wetness difference values that correspond to the change events of interest (change in forest cover area), while limiting errors of omission and commission (Skakun et al. 2003). The identified change events were intersected with the NFI photo plots to determine the total number of plots with change, as well as the area of change within each photo plot.

\section{MODIS percent forest cover loss product}

Details on the creation of the MODIS forest cover loss product for the boreal forest area used in this study are provided in Potapov et al. (2008). The MODIS data input to this approach initially included an annual set of 11 32-day composites (composed of seven land bands, derived NDVI, and down-sampled land surface temperature) and an additional 190 annual spectral metrics designed to capture phenological variation. A subset of the most meaningful inputs was defined, reducing the number of MODIS inputs from 289 to 95. Regression tree analysis was then employed to produce annual and interannual estimates of panboreal forest loss for each 500-m MODIS pixel. A threshold was applied to these estimates to generate a 2000-2005 forest-loss indicator map. This map was used to stratify the biome into regions of low, medium, and high levels forest cover loss. Subsequent samples of Landsat data per stratum were used to quantify area of forest cover loss for the entire biome.

\section{Comparison of land-cover change products}

Large area, synoptic estimates of changes in forest area between 2000 and 2005 were generated by summarizing the MODIS forest cover loss product by ecoregion and by NFI photo plot. To assess the representativeness of the NFI photo plots as a sample, we compared the proportion of annual forest area change (from the MODIS product) within the ecoregions, to the proportion of annual forest area change within the NFI photo plots within the ecoregions. This comparison allowed us to assess how the change estimates generated from the NFI sample compared with the full sample of ecoregion-level change enabled by the spatially extensive coverage of the MODIS data. The NFI photo plots were intersected separately with the MODIS- and Landsat-derived change events to identify and compare the number of photo plots with change, as well as the relative proportion of changed area within each photo plot. The results of the data intersection were then compared using a standard error matrix. Finally, in order to assess the suitability of the MODIS product to serve as an alarm system that could guide the acquisition of higher resolution image sources, we intersected the MODIS change events against the Landsat frames corresponding to our study area.

Due to the small size of the NFI photo plots in relation to the spatial resolution of the MODIS and the likelihood for misregistration of these data layers, reprojection and resampling of the MODIS imagery were not undertaken. Rather, MODIS rasters were vectorized and attributed with their underlying cell values (i.e., year of change). These vectors were then reprojected from the sinusoidal projection to the same projection as the other data layers (Universal Transverse Mercator (UTM)), facilitating standard overlay and intersection techniques using GIS software. Thus, as per the change events identified through the Landsat WDI approach, the number of photo plots intersected by the MODIS change events could be identified, as could the relative area of change within each photo plot. When converted to the UTM projection, each MODIS change product pixel covers an area of approximately $9 \times 15$ full Landsat pixels, oriented at $\mathrm{a}-30^{\circ}$ angle (Fig. 3). 


\section{Results}

The MODIS change product identified the location and extent of areas that experienced changes in forest cover by year, from 2000 to 2005 (Potapov et al. 2008) (Fig. 4). Changes in forest area during this time were spatially concentrated in the Lake Nipigon, Big Trout Lake, Abitibi Plains, and Thunder Bay-Quetico ecoregions, while other ecoregions such as the Hudson Bay Lowlands had very little change in forest area. The size distribution of change events was also characterized and compared among ecoregions (Fig. 5) and indicated that the Lake Nipigon ecoregion contained the majority of change events and that more of these events were of a larger size, relative to other ecoregions.
Of the 2,170 NFI photo plots within the study area, 263 were identified by the MODIS product as having had changes in forest cover area. A comparison of the annual proportion of change within the ecoregions to the annual proportion of change within the NFI photos plots within the ecoregions indicated that these two estimates of change are very similar (for all years; $R^{2}=0.95$ ) (Fig. 6). From this, we concluded that the NFI photo plots were a representative sample of the change in forest area found within the larger ecoregion units. A sample NFI photo plot is shown in Fig. 7.

Table 3 summarizes the results of intersecting the NFI photo plots with the Landsat and MODIS change products in a standard error matrix format that enumerates the number of NFI photo plots with changes in forest cover area (as identified

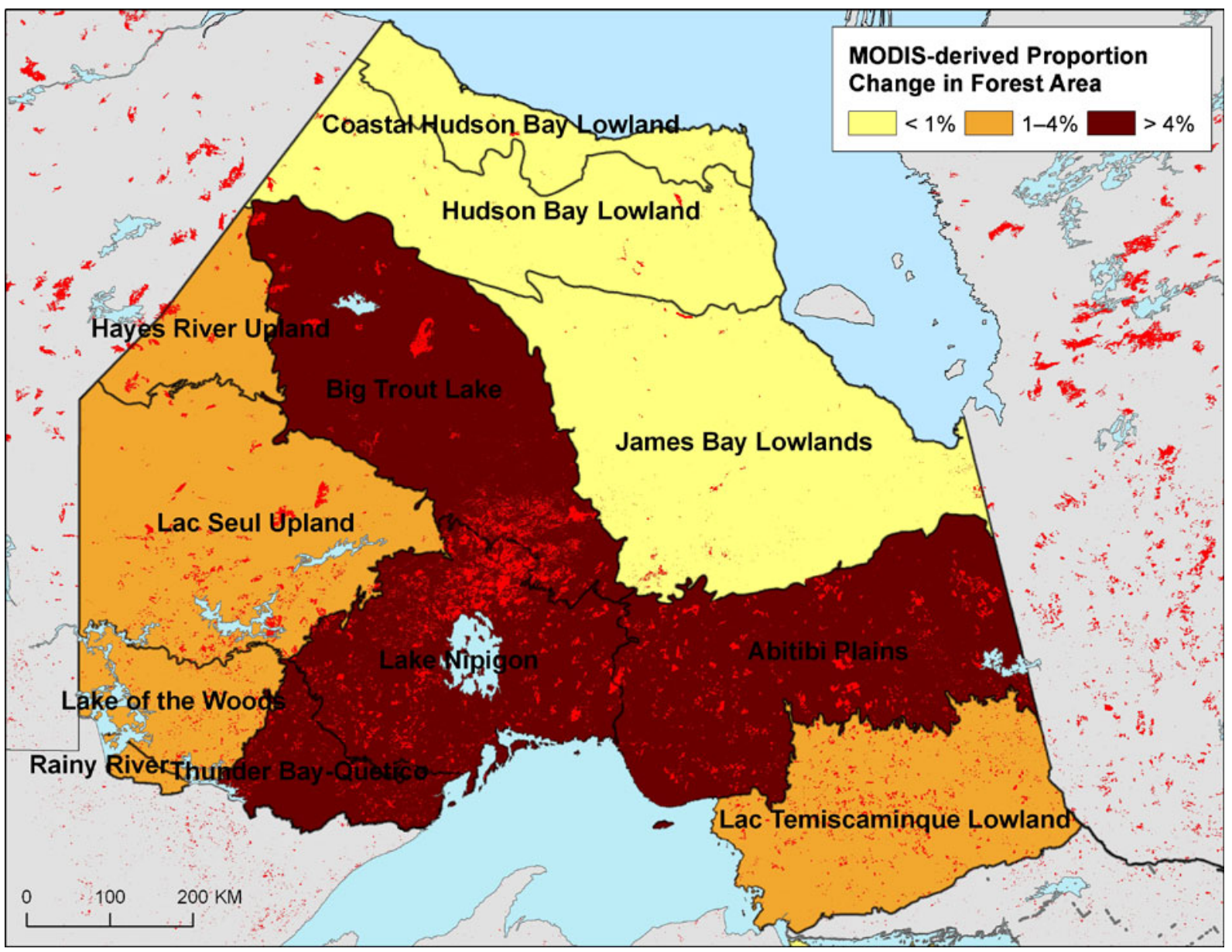

Fig. 4 MODIS-derived change in forest area, by ecoregion 
Fig. 5 Size distribution of MODIS change events for selected ecoregions
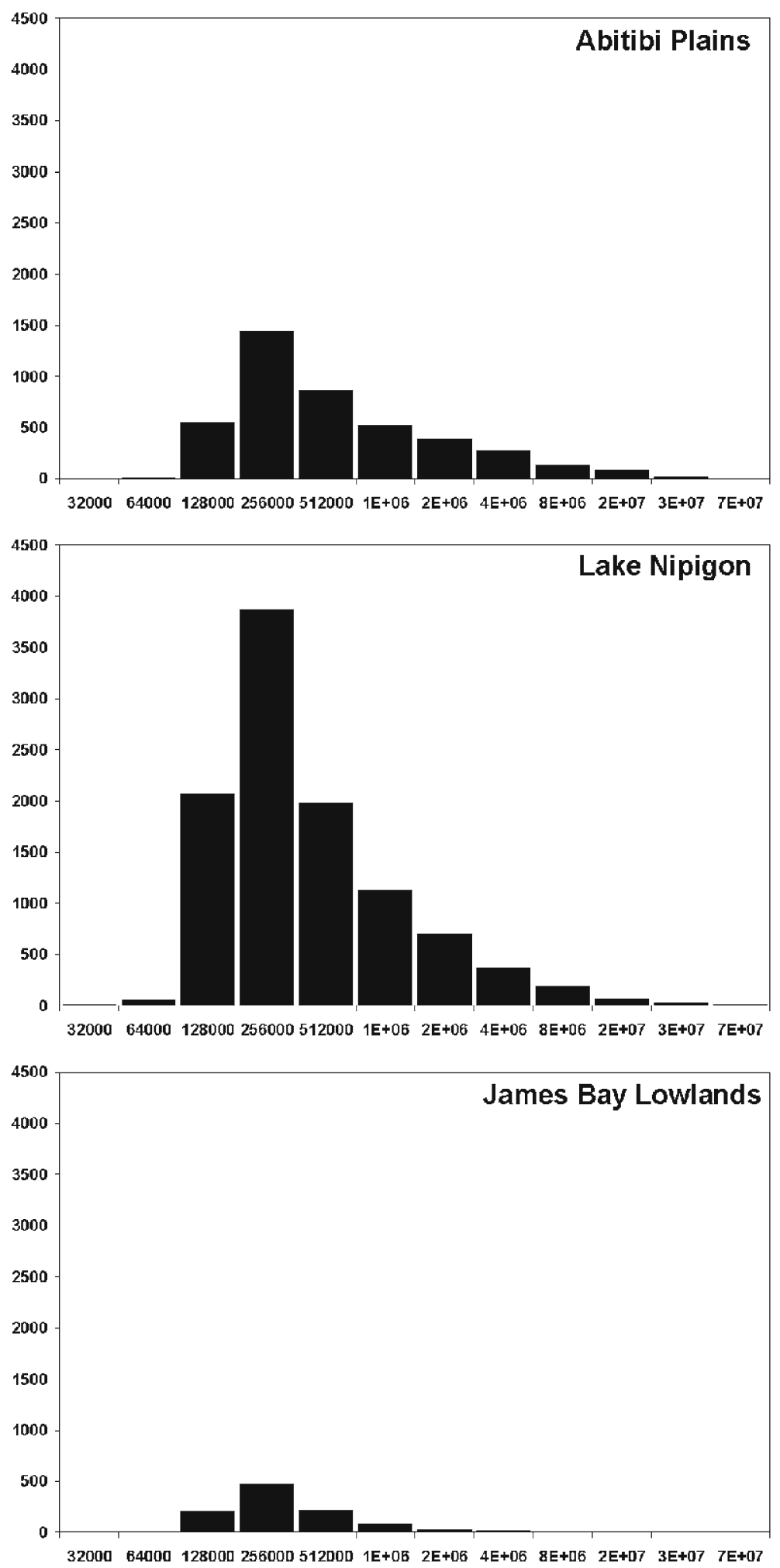
Fig. 6 MODIS-derived change in forest area (NFI photo plot versus ecoregion)

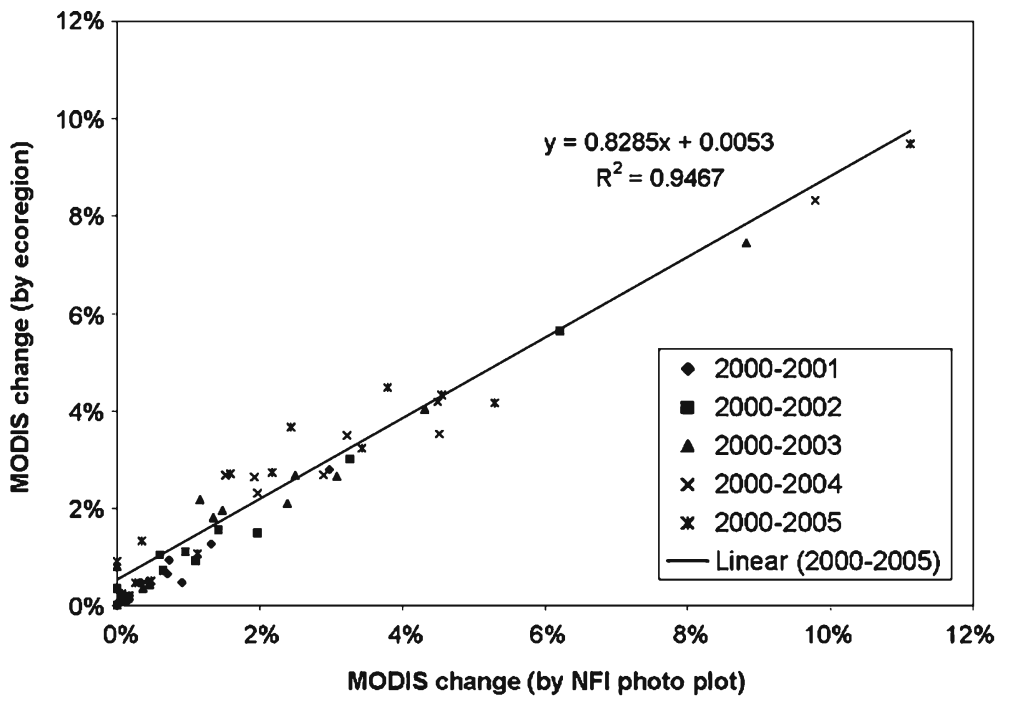

of Landsat's greater spatial resolution, but also because ancillary data sources (Table 1) were used to vet and calibrate the change events identified with the Landsat wetness difference approach. Using the Landsat-derived change as validation
Fig. 7 Sample NFI photo plot with photo-interpreted linework (yellow), Ontario Forest Information Data (2006) Landsat Wetness Difference Index change (blue), and MODIS change vectors (red)

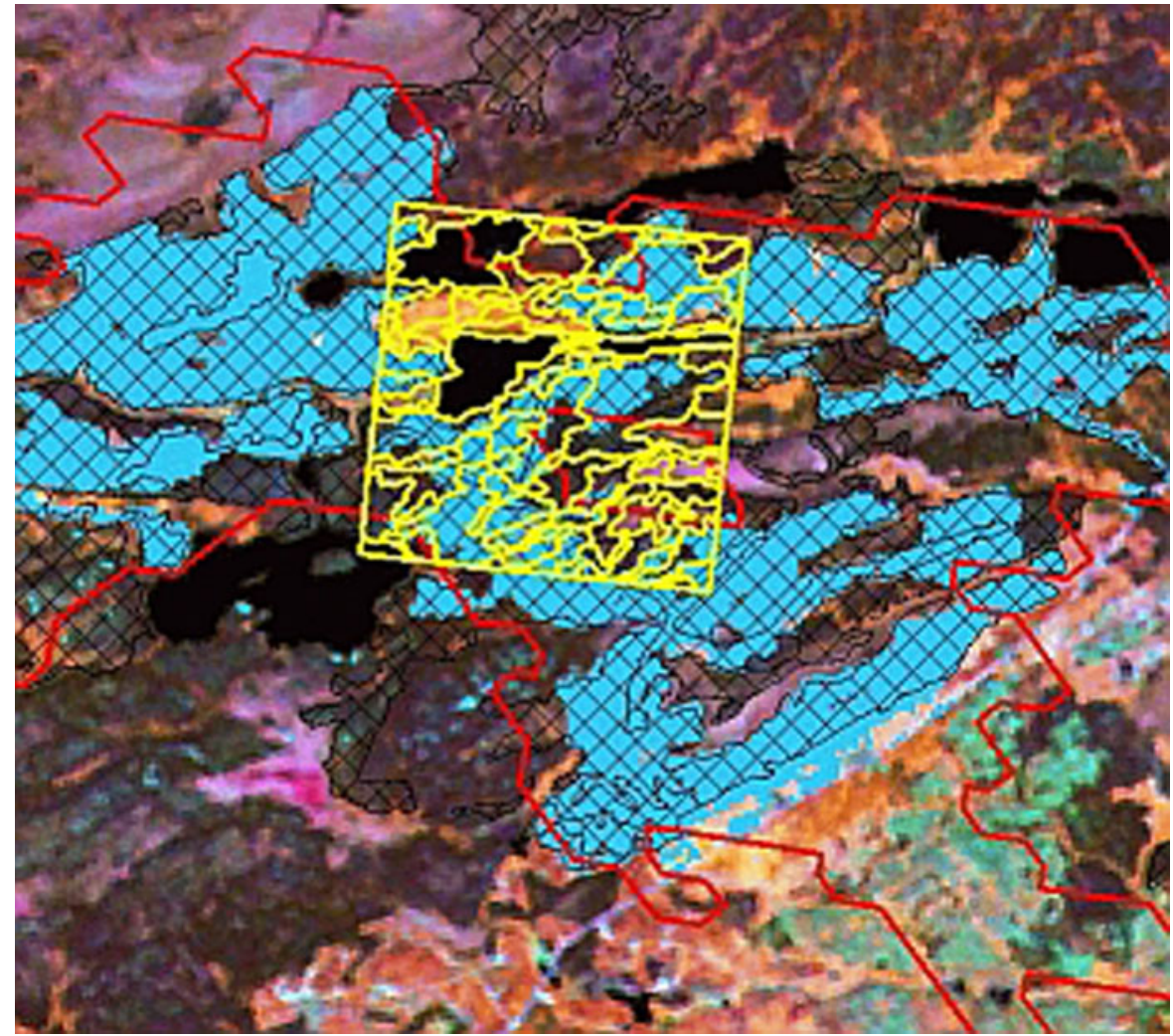


Table 3 Confusion matrix for MODIS identification of change and no change within NFI photo plots

\begin{tabular}{llcccll}
\hline \multicolumn{5}{c}{ MODIS } & & \\
\cline { 3 - 6 } & & Change & No change & Sum & Producer's & Omission \\
\hline Landsat & Change & 107 & 31 & 138 & $78 \%$ & $22 \%$ \\
& No change & 21 & 78 & 99 & $79 \%$ & $21 \%$ \\
& Sum & 128 & 109 & 237 & & \\
& User's & $84 \%$ & $72 \%$ & & Overall accuracy $=78 \%$ \\
& Commission & $16 \%$ & $28 \%$ & & $95 \%$ confidence interval $(72-83 \%)$ \\
\hline
\end{tabular}

data for the MODIS, we see that the MODIS had an overall accuracy of $78 \%$, and that the true positive rate for detection of forest change (producer's accuracy) was also 78\% (Table 3).

Of the 107 photo plots that both data sources identified as containing change events, we compared the proportion of area changed within each of the photo plots. Fitting the data linearly produced an $R^{2}$ of 0.78 , a $y$-intercept at $5 \%$, and a slope of 0.58 (Fig. 8). Approximately $22 \%$ of the changed photo plots identified with Landsat were not identified by the MODIS approach, and these omissions mostly straddled the $y$-intercept and may indicate an average detectable minimum for forest cover change detection with the MODIS approach. The maximum proportion of sub-pixel forest cover change not detected by the MODIS approach was $20 \%$, while the average proportion of sub-pixel forest cover change was $5 \%$. This corresponds to the 5\% sub-pixel change threshold selected by Potapov et al. (2008) for forest cover loss hot spot mapping (this threshold yielded the lowest combined omission and commission error rate). Approximately $16 \%$ of the photo plots identified by the MODIS as having changed were not identified with the Landsat approach (commission error) (Table 3), and some of this error is attributable to the time lag between the Landsat and MODIS imagery (the T2 MODIS image used in the change analysis was acquired in March 2006, whereas the T2 date for the Landsat images varied, see Table 2).

Figure 9 indicates the sub-pixel resolvability of the MODIS forest cover loss product, as assessed against the Landsat change events. The MODIS change product had a spatial resolution of approximately $463 \times 463 \mathrm{~m}$ (or approximately $21 \mathrm{ha}$ ), while the Landsat product had a spatial resolution of $30 \times 30 \mathrm{~m}$ (or approximately $0.09 \mathrm{ha}$ ). The cumulative size distribution of the Landsat change events, as shown in Fig. 9, indicates that approximately $50 \%$ of change events occupied less than
Fig. 8 MODIS- versus Landsat-derived change in forest cover area, by photo plot

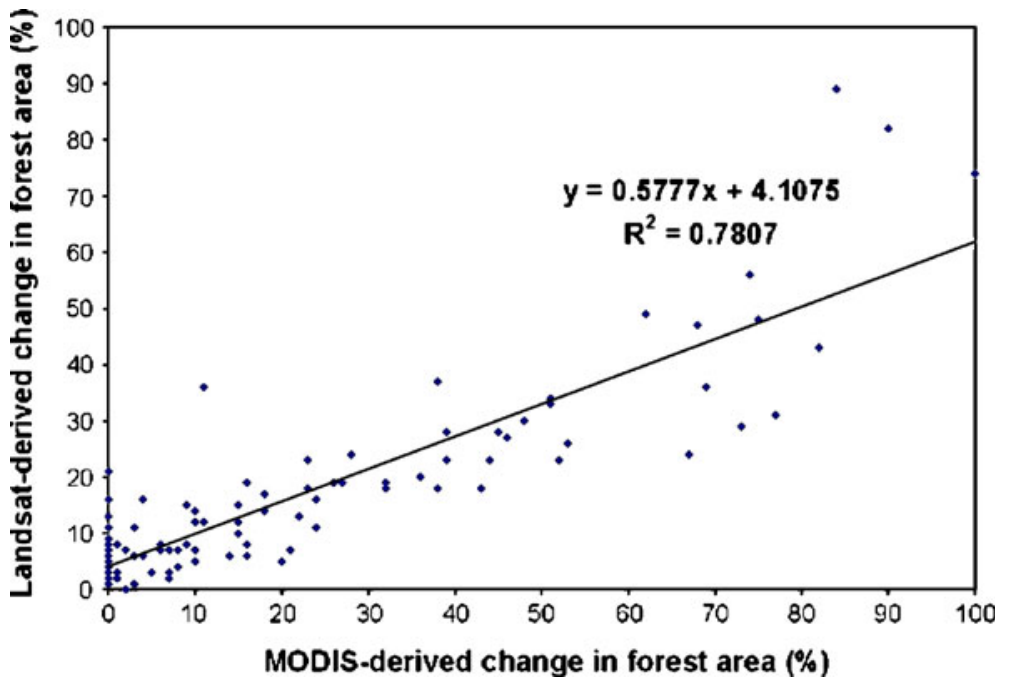


Fig. 9 Size distribution of Landsat-derived change events and resolvability of MODIS
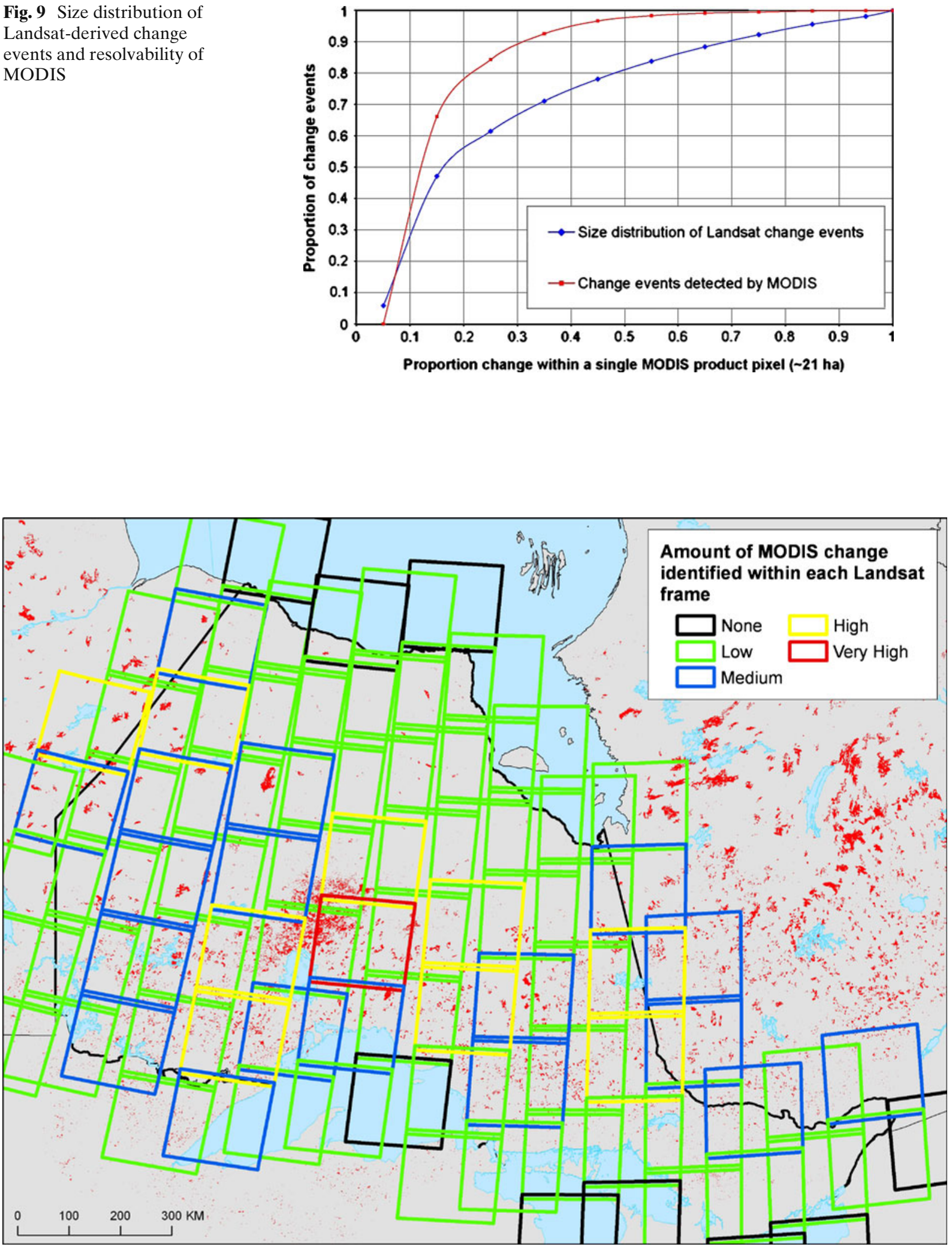

Fig. 10 MODIS change by Landsat frame (note that most frames contain some change) 
$20 \%$ of a single MODIS product pixel (i.e., were less than 4 ha in size). As expected, the proportion of change events captured by MODIS increased as the amount of change area within each MODIS pixel increased-more than $90 \%$ of change events that occupied at least $50 \%$ of the MODIS pixel (i.e., 10 ha) were detected.

The results of the intersection of the MODIS change events with the Landsat frames corresponding to our study area indicate that changes in forest cover are spatially widespread (Fig. 10), with most of the Landsat frames in the study area having some changes in forest cover. Thus, although, using the MODIS change product to direct the subsequent acquisition of higher spatial resolution image sources may not provide operational image acquisition economies, there may be specific disturbance events that could be further investigated by acquiring higher spatial resolution imagery (such as improving the spatial precision of fire boundaries).

\section{Discussion}

Remotely sensed data may be used to characterize land cover over large areas, with the spatial resolution of the sensor dictating the information content of the resultant classification (Cihlar 2000). The common tradeoff in remote sensing is between temporal and spatial resolution: MODIS has a low spatial resolution but acquires images daily and may be utilized to produce annual depictions of land cover and land-cover change. Landsat has a higher spatial resolution but acquires images at any given location only once every 16 days; the longer revisit cycle of Landsat sensors inhibits the annual capture of land cover or disturbance since the likelihood of acquiring cloud-free imagery during the growing season is substantially reduced (Ju and Roy 2007).

The use of the MODIS forest change product generated by Potapov et al. (2008) or a similar product, for assessing change at the NFI photo plot level is not without challenges. For example, MODIS pixels may straddle NFI photo plot boundaries and, therefore, may be subject to change events occurring external to the photo plot. Furthermore, great care must be taken in projecting MODIS data or derived products to ensure alignment with other spatial layers. Notwithstanding these concerns, MODIS has demonstrated capability for assessing changes in forest cover and identifying stand-replacing disturbance events across broader ecological units (Potapov et al. 2008).

Other studies have found similar resolvability results with MODIS to those reported herein. Lunetta et al. (2006) used a multitemporal MODIS NDVI 16-day composite for automated change detection over an estuary system. Approximately $96 \%$ of the change they identified represented an area corresponding to $40 \%$ of a MODIS pixel, while $71 \%$ of the omissions were MODIS pixels with $\leq 20 \%$ change. Zhan et al. (2002) used MODIS data and various change detection algorithms to map wildfires, floods, and deforestation events. Accuracy for deforestation events using the Vegetation Cover Conversion algorithm was $74 \%$ (no minimum size was given for deforestation events). Morton et al. (2005) used MODIS data and a suite of change detection algorithms to assess deforestation in the Brazilian Amazon and found that several of the algorithms were able to identify more than $80 \%$ of deforestation events $>3$ ha in size and that all algorithms identified polygons $>20$ ha in size and had low commission errors.

The criteria selected for the processing of the MODIS and Landsat images used in this study may have impacted the detectability results achieved. First, the MODIS-based analysis of forest cover changes between 2000 and 2005 was only conducted for those areas determined to have forest cover in 2000. To reduce commission error, forest cover was defined as those MODIS VCF pixels with greater than $25 \%$ forest cover (Potapov et al. 2008). The RMS error of the MODIS VCF product for sites tested thus far is 11.5\% (Hansen et al. 2002; Carroll et al. in press). A separate analysis mask was generated for the Landsat change detection approach using a classification tree and Landsat ETM+bands 2-7 and NDVI. A $50 \%$ forest class likelihood threshold was used to define forest in the Landsat data in 2000. In an operational context, a forest stratum could be identified from a single year and a single data source. Potapov et al. (2008) note that the 
use of high spatial resolution training data with MODIS inputs could improve the detectability of smaller changes in forest cover, and the use of precise water, wetland, and forest masks would reduce errors of commission.

Potapov et al. (2008) employed MODIS data to guide the stratification of Landsat sample blocks and to refine area change estimation through a regression estimator procedure. Alternatively, more direct calibration of the per-pixel MODIS percent forest cover loss maps is possible. Lunetta et al. (2006) applied an adjustment factor to sub-pixel MODIS estimates of changed area. If the NFI were to use MODIS to monitor forest change, such methods would be required to meet reporting standards.

The MODIS change product described herein captures changes in forest canopy cover. A perpixel fraction of forest cover loss is generated and may be used to further categorize the change into classes or to create a binary change/no change mask. Changes in forest cover, as detected by the MODIS product, do not necessarily equate to the same types of forest changes that are routinely captured systematically by forest management agencies (e.g., harvest, fire, and insects). Changes to canopy cover resulting from snow damage, drought stress, blow down, or other similar factors may not be captured as part of inventory surveys unless the changes are spatially extensive or are located in operationally important management units. For instance, the large area of forest change located in the Lake Nipigon ecoregion (just north of Lake Nipigon, see Fig. 4) is due to a 40-50 cm snow fall on October 24, 2001, which caused broad-area, low-intensity forest damage, as characterized by blow down and broken tree tops over a large area (http://www. wabakimi.on.ca/wabakimi/maps_and_safety.htm). Therefore, changes in canopy cover, as detected by the MODIS or a similar image product, must be considered as complementary, but not identical, to changes that are routinely captured and reported in forest inventories.

Given the size of Canada's forested area and the remeasurement cycle of the NFI program, annual reconnaissance-level information on the location and extent of stand replacing disturbance is preferable to having no information on forest disturbance in the years between NFI remeasurement. Annual MODIS forest cover change products will likely be available in the near future, or may be generated by the NFI program using existing methodologies. Larger and more intense changes in forest cover such as harvesting or fires would be captured by MODIS change products and although some smaller changes may be missed, they will likely accumulate and be detectable in subsequent years. Many disturbance events in the boreal are quite large. For example, between 1959 and 1997, only 3\% of forest fires in Canada were $>200$ ha in size; however, these fires accounted for more than $97 \%$ of the total area burned annually (Stocks et al. 2003).

Additional monitoring opportunities exist to combine the spatial detail of Landsat with the temporal richness of MODIS to create synthetic image products (Hilker et al. 2009). The data fusion algorithm implemented by Hilker et al. (2009) has the spatial detail guided by Landsat with the spectral values on a pixel basis formed by MODIS. The algorithm and processing approach also enables detection and dating of change from a MODIS series of images (using a Landsat-based change mask as a guide). Future research may also include investigating the potential of the $250 \mathrm{~m}$ MODIS channels to support large area monitoring programs through improved spatial precision in the subsequent change products developed.

\section{Conclusion}

Agencies responsible for forest monitoring and reporting require data that are available over large areas and that also confer detailed information on land cover composition and change. To meet these often contrasting requirements, sample based forest inventories are commonly employed. These sample-based inventories are typically implemented over multiple years, resulting in an inventory relating conditions and change present over a given period of time. High-temporal, low-spatial resolution imagery such as MODIS, in combination with other data sources, can provide information on forest changes (primarily disturbances) 
within these measurement cycles. Information on annual changes in Canada's forest cover is useful to inform national and international reporting requirements, and to keep policy and decision makers abreast of current forest conditions. In this paper, we presented a framework for incorporating this information into the NFI context, and demonstrate the capability of a MODISderived change product for detecting and mapping changes in forest cover.

When compared to a higher resolution depiction of forest cover change from Landsat change analysis for a similar time period, the MODIS provided complementary information on both the location and amount of forest cover change. Furthermore, the large area coverage of the MODIS afforded ecoregion-wide estimates of annual change, enabling augmentation of the large-area, sample-based NFI. The use of hightemporal, low-spatial resolution remotely sensed data provides useful information in a large area forest monitoring framework. Whereas more detailed information (both spatially and categorically) will form the foundation of any samplebased, large-area forest inventory, the provision of temporally dense information on forest disturbances within the inventory cycle provides valuable insights on current forest conditions. The findings presented here are envisioned as applicable and portable to other large forested nations that implement a national forest inventory.

Acknowledgements This research was undertaken as part of the "EcoMonitor: Northern ecosystem climate change monitoring" project jointly funded by the Canadian Space Agency (CSA) Government Related Initiatives Program (GRIP) and the Canadian Forest Service (CFS) of Natural Resources Canada. Joe Kapron and Larry Watkins of the Ontario Ministry of Natural Resources are thanked for insights aiding in the project implementation and for provision of important data layers.

Open Access This article is distributed under the terms of the Creative Commons Attribution Noncommercial License which permits any noncommercial use, distribution, and reproduction in any medium, provided the original author(s) and source are credited.

\section{References}

Ahl, D. E., Gower, S. T., Burrows, S. N., Shabanov, N. V., Myneni, R. B., \& Knyazikhin, Y. (2006). Monitoring spring canopy phenology of a deciduous broadleaf forest using MODIS. Remote Sensing of Environment, 104, 88-95.

Anaya, J. A., Chuvieco, E., \& Palacios-Orueta, A. (2009). Aboveground biomass assessment in Colombia: A remote sensing approach. Forest Ecology and Management, 257, 1237-1246.

Baccini, A., Laporte, N., Goetz, S. J., Sun, M., \& Dong, H. (2008). A first map of tropical Africa's above-ground biomass derived from satellite imagery. Environmental Research Letters, 3. doi:10.1088/ 1748-9326/3/4/045011.

Bormann, F. H., \& Likens, G. E. (1979). Pattern and process in a forested ecosystems. New York: SpringerVerlag.

Bucha, T., \& Stibig, H.-J. (2008). Analysis of MODIS imagery for detection of clear cuts in the boreal forest in north-west Russa. Remote Sensing of Environment, 112, 2416-2429.

Carroll, M., Townshend, J. R. G., Hansen, M. C., DiMiceli, C., Sohlberg, R., \& Wurster, K. (in press). Vegetative cover conversion and vegetation continuous fields. In B. Ramachandran, C. Justice, \& M. Abrams (Eds.), Land remote sensing and global environmental change: NASA's EOS and the science of ASTER and MODIS. New York: Springer.

Cihlar, J. (2000). Land cover mapping of large areas from satellites: Status and research priorities. International Journal of Remote Sensing, 21, 1093-1114.

Coops, N. C., Ferster, C. J., Waring, R. H., \& Nightingale, J. (2009). Comparison of three models for predicting gross primary production across and within forested ecoregions in the contiguous United States. Remote Sensing of Environment, 113, 680-690.

Crist, E. P., \& Cicone, R. C. (1984). Application of the tasseled cap concept to simulated Thematic Mapper data. Photogrammetric Engineering and Remote Sensing, 50, 343-352.

Cuevas-Gonzàlez, M., Gerard, F., Balzter, H., \& Riano, D. (2009). Analysis of vegetation dynamics after wildfire disturbance in Siberian boreal forests using remote sensing. Global Change Biology, 15, 561-577.

deGroot, W. J., Landry, R., Kurz, W. A., Anderson, K. R., Englefield, P., Fraser, R. H., et al. (2007). Estimating direct carbon emissions from Canadian wildland fires. International Journal of Wildland Fire, 16, 593-606.

Ecological Stratification Working Group (1996). A national ecological framework for Canada. Agriculture and Agri-Food Canada, Research Branch, Centre for Land and Biological Resources Research, and Environment Canada, State of the Environment Directorate, Ottawa. http://sis.agr.gc.ca/cansis/publications/ ecostrat/cad_report.pdf. Accessed 25 May 2009.

Englefield, P., Lee, B. S., Fraser, R. H., Landry, R., Hall, R. J., Lynham, T. J., et al. (2004). Applying geographic 
information systems and remote sensing to forest fire monitoring, mapping and modelling in Canada. In R. T. Engstrom, K. E. M. Galley, \& W. J. de Groot (Eds.), Proceedings of the 22nd tall timbers fire ecology conference: Fire in temperate, Boreal and Montane ecosystems (pp. 240-245). Tallahassee: Tall Timbers Research Station.

Gao, F., Masek, J., Schwaller, M., \& Hall, F. (2006). On the blending of the Landsat and MODIS surface reflectance: Predicting daily Landsat surface reflectance. Transactions on Geoscience and Remote Sensing, 44, 2207-2218.

Gillis, M. D. (2001). Canada's National Forest Inventory (Responding to current information needs). Environmental Monitoring and Assessment, 67, 121-129.

Gillis, M. D., Omule, A. Y., \& Brierley, T. (2005). Monitoning Canada's forests: The national forest inventory. The Forestry Chronicle, 81, 214-221.

Hais, M., Jonášová, M., Langhammer, J., \& Kučera, T. (2009). Comparison of two types of forest disturbance using multitemporal Landsat TM/ETM + imagery and field vegetation data. Remote Sensing of Environment, $113,835-845$.

Han, T., Wulder, M. A., White, J. C., Coops, N. C., Alvarez, M. F., \& Butson, C. (2007). An efficient protocol to process Landsat images for change detection with tasselled cap transformation. IEEE Geoscience and Remote Sensing Letters, 4, 147-151.

Hansen, M. C., DeFries, R. S., Townshend, J. R. G., Sohlberg, R., Carroll, M., \& Dimiceli, C. (2002). Towards an operational MODIS continuous field of percent tree cover algorithm: Examples using AVHRR and MODIS data. Remote Sensing of Environment, 83, 303-319.

Hansen, M. C., DeFries, R. S., Townshend, J. R. G., Carroll, M., Dimiceli, C., \& Sohlberg, R. A. (2003). Global percent tree cover at a spatial resolution of 500 meters: First results of the MODIS Vegetation Continuous Fields Algorithm. Earth Interactions, 7, $1-15$.

Hansen, M. C., Roy, D. P., Lindquist, E., Adusei, B., Justice, C. O., \& Alstatt, A. (2008a). A method for integrating MODIS and Landsat data for systematic monitoring of forest cover and change in the Congo Basin. Remote Sensing of Environment, 112, 2495-2513.

Hansen, M. C., Shimabukuro, Y. E., Potapov, P., \& Pittman, K. (2008b). Comparing annual MODIS and PRODES froest cover change data for advancing monitoring of Brazilian forest cover. Remote Sensing of Environment, 112, 3784-3793.

Hawbaker, T. J., Radeloff, V. C., Syphard, A. D., Zhu, Z. L., \& Stewart, S. I. (2008). Detection rates of the MODIS active fire product. Remote Sensing of Environment, 112, 2656-2664.

Hilker, T., Wulder, M. A., Coops, N. C., Linke, J., McDermid, G., Masek, J. G., et al. (2009). A new data fusion model for high spatial- and temporal-resolution mapping of forest disturbance based on Landsat and MODIS. Remote Sensing of Environment, 113, 1613-1627.
Jin, S. M., \& Sader, S. A. (2005). MODIS time-series imagery for forest disturbance detection and quantification of patch size effects. Remote Sensing of Environment, 99, 462-470.

Ju, J., \& Roy, D. P. (2007). The availability of cloud-free Landsat ETM + data over the conterminous United States and globally. Remote Sensing of Environment, 112, 1196-1211.

Justice, C. O., Townshend, J. R. G., Vermote, E. F., Masuoka, E., Wolfe, R. E., Saleous, N., et al. (2002). An overview of MODIS land data processing and product status. Remote Sensing of Environment, 83, 3-15.

$\mathrm{Kim}, \mathrm{S}$. (2008). Onset date of forest canopy detected from MODIS leaf area index. Journal of Ecology and Field Biology, 31, 153-159.

Lee, B. S., Alexander, M. E., Hawkes, B. C., Lynham, T. J., Stocks, B. J., \& Englefield, P. (2002). Information systems in support of wildand fire management decision making in Canada. Computers and Electronics in Agriculture, 37, 185-198.

Lunetta, R. S., Knight, J. F., Ediriwickrema, J., Lyon, G. L., \& Worthy, L. D. (2006). Land-cover change detection using multi-temporal MODIS NDVI data. Remote Sensing of Environment, 105, 142-154.

Metsaranta, J. M., \& Lieffers, V. J. (2009). Using dendrochronology to obtain annual data for modelling stand development: A supplement to permanent sample plots. Forestry, 82, 163-173.

Morton, D. C., DeFries, R. S., Shimabukuro, Y. E., Anderson, L. O., Espírito-Santo, F. D. B., Hansen, M., et al. (2005). Rapid assessment of annual deforestation in the Brazilian Amazon using MODIS data. Earth Interactions, 9, 1-22.

Peckham, S. D., Ahl, D. E., Serbin, S. P., \& Gower, S. T. (2008). Fire-induced changes in green-up and leaf maturity of the Canadian boreal forest. Remote Sensing of Environment, 112, 3594-3603.

Peng, C. (2000). Understanding the role of forest simulation models in sustainable forest management. Environmental Impact Assessment Review, 20, 481-501.

Potapov, P., Hansen, M. C., Stehman, S. V., Loveland, T. R., \& Pittman, K. (2008). Combining MODIS and Landsat imagery to estimate and map boreal forest cover loss. Remote Sensing of Environment, 112, 3708-3719.

Power, K., \& Gillis, M. (2006). Canada's Forest Inventory 2001. Information Report BC-X-408 (140 p.). Natural Resources Canada, Canadian Forest Service, Victoria.

Skakun, R. S., Wulder, M. A., \& Franklin, S. E. (2003). Sensitivity of the thematic mapper enhanced wetness difference index to detect mountain pine beetle redattack damage. Remote Sensing of Environment, 86, 433-443.

Stocks, B. J., Mason, J. A., Todd, J. B., Bosch, E. M., Wotton, B. M., Amiro, B. D., et al. (2003). Large forest fires in Canada, 1959-1997. Journal of Geophysical Research, 108. doi:10.1029/2001JD000484.

Wang, F., \& Xu, X. J. (2009). Comparison of remote sensing change detection techniques for assessing hurricane damage to forests. Environmental Monitoring and Assessment. doi:10.1007/s10661-009-0798-8. 
Wu, J. B., Xiao, X. M., Guan, D. X., Shi, T. T., Jin, C. J., \& Han, S. J. (2009). Estimating the gross primary production of an old-growth temperate mixed forest using eddy covariance and remote sensing. International Journal of Remote Sensing, 30, 463-479.

Wulder, M. A., Kurz, W. A., \& Gillis, M. (2004). National level forest monitoring and modeling in Canada. Progress in Planning, 61, 365-381.
Wulder, M. A., White, J. C., Bentz, B., Alvarez, M. F., \& Coops, N. C. (2006). Estimating the probability of mountain pine beetle red-attack damage. Remote Sensing of Environment, 101, 150-166.

Zhan, X., Sohlberg, R. A., Townshend, J. R. G., DiMiceli, C., Carroll, M. L., Eastman, J. C., et al. (2002). Detection of land cover changes using MODIS $250 \mathrm{~m}$ data. Remote Sensing of Environment, 83, 336-350. 